\title{
Kinetic, mechanistic and spectral investigation of ruthenium (III)- catalysed oxidation of atenolol by alkaline permanganate (stopped-flow technique)
}

\author{
RAHAMATALLA M MULLA, GURUBASAVARAJ C HIREMATH and \\ SHARANAPPA T NANDIBEWOOR* \\ PG Department of Studies in Chemistry, Karnatak University, Dharwad 580 003, India \\ e-mail: stnandibewoor@yahoo.com
}

MS received 10 October 2003; revised 26 December 2003

\begin{abstract}
Kinetics of ruthenium (III) catalyzed oxidation of atenolol by permanganate in alkaline medium at constant ionic strength of $0.30 \mathrm{~mol} \mathrm{dm}^{3}$ has been studied spectrophotometrically using a rapid kinetic accessory. Reaction between permanganate and atenolol in alkaline medium exhibits $1: 8$ stoichiometry (atenolol : $\mathrm{KMnO}_{4}$ ). The reaction shows first-order dependence on [permanganate] and [ruthenium (III)] and apparently less than unit order on both atenolol and alkali concentrations. Reaction rate decreases with increase in ionic strength and increases with decreasing dielectric constant of the medium. Initial addition of reaction products does not affect the rate significantly. A mechanism involving the formation of a complex between catalyst and substrate has been proposed. The active species of ruthenium (III) is understood as $\left[\mathrm{Ru}\left(\mathrm{H}_{2} \mathrm{O}\right)_{5} \mathrm{OH}\right]^{2+}$. The reaction constants involved in the different steps of mechanism are calculated. Activation parameters with respect to the slow step of the mechanism are computed and discussed and thermodynamic quantities are also calculated.
\end{abstract}

Keywords. Kinetics; permanganate; stopped-flow technique; oxidation of atenolol; ruthenium(III) catalysis.

\section{Introduction}

Permanganates ions oxidize a greater variety of substrates and find extensive applications in organic syntheses, ${ }^{1-7}$ especially after the advent of phasetransfer catalysis, ${ }^{3,4,6}$ which permits the use of solvents such as methylene chloride and benzene. Kinetic studies constitute an important source of mechanistic information on the reaction, as demonstrated by results referring to unsaturated acids in both aqueous s, $^{1,7}$ and non-aqueous media. ${ }^{8}$

During oxidation by permanganate, it is evident that the Mn(VII) in permanganate is reduced to various oxidation states in acidic, alkaline and neutral media. Furthermore, the mechanism by which this multivalent oxidant oxidizes a substrate depends not only on the substrate but also on the medium ${ }^{9}$ used for the study. In strongly alkaline media, the stable reduction product ${ }^{10,11}$ is the manganate ion, $\mathrm{MnO}_{4}^{2-}$. No mechanistic information is available to distinguish between direct one-electron reduction to $\mathrm{Mn}(\mathrm{VI})$

*For correspondence (scheme 1) and one in which a hypomanganate is formed in a two-electron step followed by rapid reaction $^{12}$ (scheme 2).

4-(2-Hydroxy-3-isopropylaminopropoxy)phenylacetamide commercially known as atenolol (ATN), a $\beta$-adrenoreceptor blocking agent, is commonly used

$$
\begin{aligned}
& \operatorname{Mn}(\mathrm{VII})+S \stackrel{k_{1}^{1}}{\longrightarrow} \operatorname{Mn}(\mathrm{VI})+S^{\bullet}, \\
& \mathrm{Mn}(\mathrm{VII})+S^{\bullet} \stackrel{k_{2}^{1}}{\longrightarrow} \mathrm{Mn}(\mathrm{VI})+\text { products, } \\
& \text { where } S=\text { substrate, } k_{2}^{1} \gg k_{1}^{1} .
\end{aligned}
$$

Scheme 1.

$$
\begin{aligned}
& \mathrm{Mn}(\mathrm{VII})+S \stackrel{k_{3}^{1}}{\longrightarrow} \mathrm{Mn}(\mathrm{V})+\text { products, } \\
& \mathrm{Mn}(\mathrm{VII})+\mathrm{Mn}(\mathrm{V}) \stackrel{k_{4}^{1}}{\longrightarrow} 2 \mathrm{Mn}(\mathrm{VI}), \\
& \text { where } S=\text { substrate, } k_{4}^{1} \gg k_{3}^{1} .
\end{aligned}
$$

Scheme 2. 
as antihypertensive drug. ${ }^{13}$ It is also used for antiangina treatment to relieve symptoms, improve tolerance and as an anti-arrhythmic to regulate heartbeat and present infections. It is also used in management of alcohol withdrawal, in anxiety states, migraine prophylaxis, hyperthyroidism and tremors.

Ruthenium (III) acts as an efficient catalyst in many redox reactions, particularly in an alkaline medium. ${ }^{14}$ The catalysis mechanism can be quite complicated due to the formation of different intermediate complexes, free radicals and different oxidation states of ruthenium. The kinetics of fast reaction between ruthenate (VII), $\mathrm{RuO}_{4}^{-}$, and manganate (VI), i.e. $\mathrm{MnO}_{4}^{2-}$, have been studied, ${ }^{15}$ where the reaction is presumed to proceed via an outer-sphere mechanism. The uncatalysed reaction between atenolol and permanganate in an alkaline medium has been studied previously. ${ }^{16} \mathrm{~A}$ microscopic amount of ruthenium (III) is sufficient to catalyze the reaction and a variety of mechanisms are possible. Herein, we describe the results of the title reaction in order to understand the active species of oxidant, reductant and catalyst in such media and to arrive at a plausible mechanism.

\section{Experimental}

\subsection{Devices}

Since the initial reaction was too fast to be monitored by the usual methods, kinetic measurements were performed on a Peltier accessory (temperature control) attached Varian Cary 50 Bio UV-Vis spectrophotometer connected to a rapid kinetic accessory (HI-Tech SFA-12). IR, NMR, fluorimetry and mass spectral studies were performed by Nicolet Impact410 FT IR, Brucker $300 \mathrm{MHz}$, and Pesciex Qstar Polsar LC-MS/MS-TOF.

\subsection{Materials: Chemicals and catalyst}

All chemicals used were of reagent grade. Solution of atenolol (M/s SS Antibiotics Pvt Ltd, Aurangabad, India) was prepared by dissolving the appropriate amount of recrystalised sample in double distilled water. The solution of $\mathrm{KMnO}_{4}(\mathrm{BDH})$ was prepared by dissolving the appropriate amounts of sample in doubly distilled water and standardized ${ }^{17}$ against $\left(\mathrm{CO}_{2} \mathrm{H}\right)_{2} . \mathrm{K}_{2} \mathrm{MnO}_{4}$ solution was prepared as described by Carrington and Symons ${ }^{18}$ as follows: A solution of $\mathrm{KMnO}_{4}$ was heated to boiling in $8.0 \mathrm{~mol} \mathrm{dm}^{-3}$ $\mathrm{KOH}$ solution until a green colour appeared. The solid formed on cooling was recrystallised from the same solvent. Using the required amount of recrystallised sample, a stock solution of $\mathrm{K}_{2} \mathrm{MnO}_{4}$ was prepared in aqueous $\mathrm{KOH}$. The solution was standardized by measuring the absorbance on a Peltier accessory (temperature control) attached Varian Cary 50 Bio UV-Vis spectrophotometer with a $1 \mathrm{~cm}$ quartz cell at $608 \mathrm{~nm}\left(\varepsilon=1530 \pm 20 \mathrm{dm}^{3} \mathrm{~mol}^{-1} \mathrm{~cm}^{-1}\right)$.

The $\mathrm{Ru}(\mathrm{III})$ solution was prepared by dissolving a known weight of $\mathrm{RuCl}_{3}$ (sd Fine-Chem) in $\mathrm{HCl}$ $\left(0.20 \mathrm{~mol} \mathrm{dm}^{-3}\right) . \mathrm{Hg}$ was added to the $\mathrm{Ru}(\mathrm{III})$ solution, to reduce any $\mathrm{Ru}(\mathrm{IV})$ formed during the preparation of the $\mathrm{Ru}$ (III) stock solution, which was set aside for $24 \mathrm{~h}$. The $\mathrm{Ru}$ (III) concentration was then assayed by EDTA titration. ${ }^{19}$

All other reagents were of analytical grade and their solutions were prepared by dissolving the requisite amounts of the samples in doubly distilled water. $\mathrm{NaOH}$ and $\mathrm{NaClO}_{4}$ were used to provide the required alkalinity and to maintain the ionic strength respectively.

\subsection{Kinetic measurements}

All kinetic measurements were performed under pseudo-first order conditions with excess of [atenolol] over $\left[\mathrm{MnO}_{4}^{-}\right]$at a constant ionic strength of $0.30 \mathrm{~mol} \mathrm{dm}^{-3}$. The reaction was initiated by mixing previously thermostatted solutions of $\mathrm{MnO}_{4}^{-}$and atenolol, which also contained the necessary quantities of $\mathrm{Ru}(\mathrm{III}), \mathrm{NaOH}$ and $\mathrm{NaClO}_{4}$, to maintain the required alkalinity and ionic strength respectively. The temperature was uniformly maintained at $25 \pm 0.1{ }^{\circ} \mathrm{C}$. The course of reaction was followed by monitoring the decrease in the absorbance of $\mathrm{MnO}_{4}^{-}$in a $1 \mathrm{~cm}$ quartz cell of Peltier accessory (temperature control) attached Varian Cary 50 Bio UV-Vis spectrophotometer connected to a rapid kinetic accessory (HiTech SFA-12), at its absorption maximum of $526 \mathrm{~nm}$ as a function of time. The application of Beer's law to permanganate at $526 \mathrm{~nm}$ is verified, giving $\varepsilon=$ $2083 \pm 50 \mathrm{dm}^{3} \mathrm{~mol}^{-1} \mathrm{~cm}^{-1}$ (literature $\varepsilon=2200 \mathrm{dm}^{3}$ $\left.\mathrm{mol}^{-1} \mathrm{~cm}^{-1}\right)$. The first-order rate constants, $\left(k_{c}\right)$ were evaluated by the plots of $\log \left(A_{t}-A_{\infty}\right)$ versus time by fitting the data to the expression $A_{t}=A_{\infty}+\left(A_{0}-\right.$ $\left.A_{\infty}\right) e^{-k c . t}$, where $A_{t}, A_{0}$ and $A_{\infty}$ are absorbances of permanganate at time $t, 0$ and $\infty$ respectively. The first-order plots in almost all cases are linear to $80 \%$ completion of the reaction and $k_{c}$ is reproducible within $\pm 5 \%$. During the course of measurements, the solution changes from violet to blue and then to 
green. The spectrum of the green solution is identical to that of $\mathrm{MnO}_{4}^{2-}$. It is probable that the blue color originates from the violet of permanganate and the green from the manganate, excluding the accumulation of hypomanganate. It is also evident from figure 1 that the absorbance of permanganate decreases at $526 \mathrm{~nm}$ whereas the absorbance of manganate increases at $608 \mathrm{~nm}$.

The effect of dissolved oxygen on the rate of reaction was studied by preparing the reaction mixture and following the reaction in an atmosphere of $\mathrm{N}_{2}$. No significant difference is observed, between the results. In view of the ubiquitous contamination of basic solutions by carbonate, the effect of carbonate on the reaction was also studied. Added carbonate has no effect on reaction rate. However, fresh solutions were used during the experiments.

In view of the modest concentration of alkali used in the reaction medium, attention was also given to the effect of the surface of the reaction vessel on the kinetics. The use of polythene or acrylic ware and quartz or polyacrylate cells gave the same results,

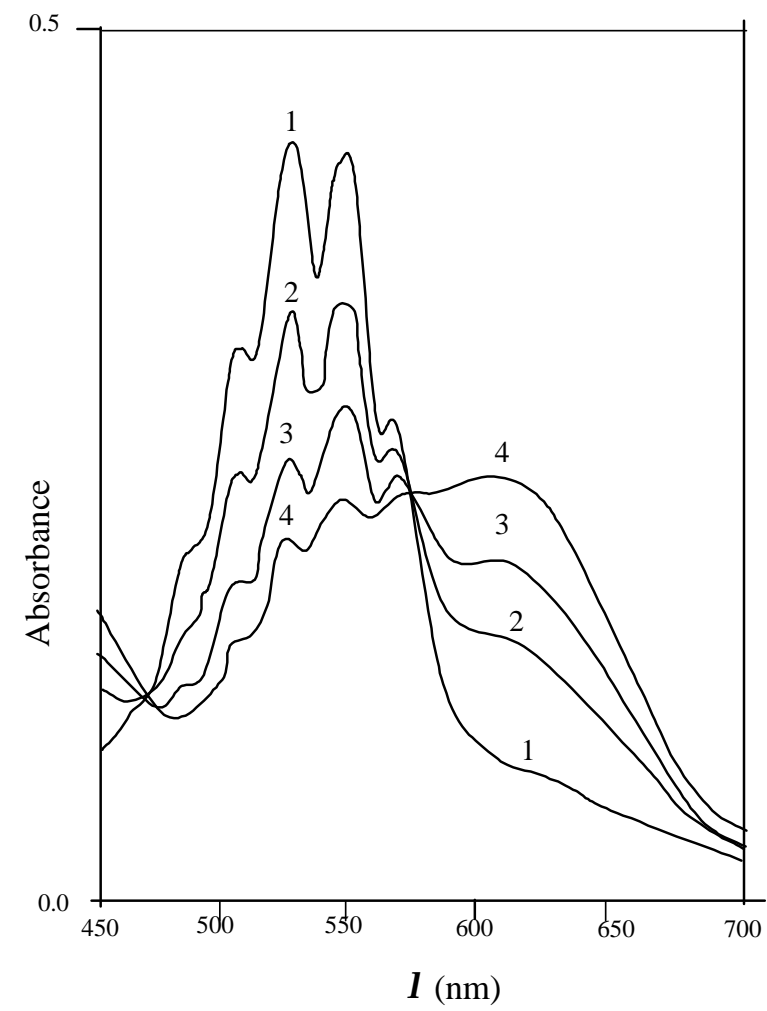

Figure 1. Spectroscopic changes occurring in the $\mathrm{Ru}(\mathrm{III})$ catalysed oxidation of atenolol by permanganate with $[\mathrm{ATN}]=1.5 \times 10^{-3},\left[\mathrm{MnO}_{4}\right]=1.5 \times 10^{-4}[\mathrm{Ru}(\mathrm{III})]=1.0 \times$ $10^{-6},\left[\mathrm{OH}^{-}\right]=0 \cdot 05$, and $I=0 \cdot 30 \mathrm{~mol} \mathrm{dm}{ }^{-3}$ at $25^{\circ} \mathrm{C}$, scanning time interval $=120 \mathrm{~s}$. indicating that the surface does not have any significant effect on the rate.

Regression analysis of experimental data to obtain the regression coefficient $r$ and standard deviation $S$ of points from the regression line was done using a Pentium-IV personal computer.

\section{Results}

\subsection{Stoichiometry and product analysis}

Reaction mixtures containing an excess permanganate concentration over atenolol and constant [ruthenium (III)], $0.05 \mathrm{~mol} \mathrm{dm}^{-3} \mathrm{NaOH}$, and adjusted to ionic strength of $0.30 \mathrm{~mol} \mathrm{dm}^{-3}$ was allowed to react for $6 \mathrm{~h}$. at $25 \pm 0.1^{\circ} \mathrm{C}$. The remaining permanganate was then analysed spectrophotometrically. The results indicated that eight moles of $\mathrm{MnO}_{4}^{-}$are consumed by one mole of atenolol as given by the reaction:

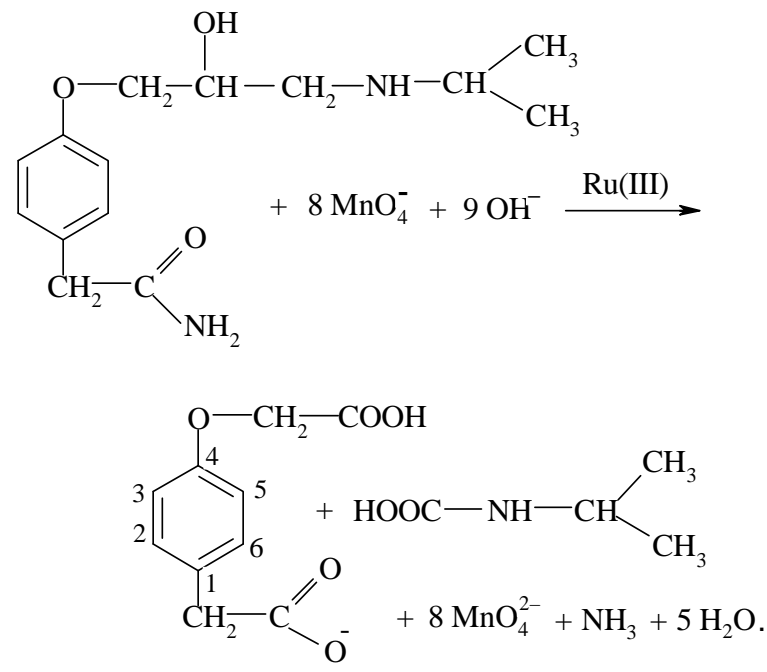

For identification of the products, the reaction mixture containing excess of atenolol was kept to allow completion of reaction. The reaction product, 4-carboxy methoxy phenyl acetic acid, was extracted with ether and recrystallised from aqueous alcohol, and its purity checked by HPLC. 4-Carboxy methoxy phenyl acetic acid was also characterised by its IR spectrum, which showed a band at (v) $1690 \mathrm{~cm}^{-1}$ due to acid $>\mathrm{C}=\mathrm{O}$ stretch and a broad band at $2845 \mathrm{~cm}^{-1}$ due to $\mathrm{O}-\mathrm{H}$ stretch. It was further characterised by ${ }^{1} \mathrm{H}$ NMR spectrum (DMSO), where it showed a singlet at $9 \cdot 6 \delta$ due to two carboxylic OH's, a doublet $(J=9 \mathrm{~Hz})$ at $6.94 \delta$ due to $\mathrm{C}_{3}$ - and 
$\mathrm{C}_{5}$-protons, another doublet $(J=9 \mathrm{~Hz})$ at $7 \cdot 20 \delta$ due to $\mathrm{C}_{2^{-}}$and $\mathrm{C}_{6}$-protons, a singlet at $3.53 \delta$ due to methylene protons of ph- $\mathrm{CH}_{2}$ - and another singlet at $4.58 \delta$ due to methylene protons of ph-O- $\mathrm{CH}_{2}$ - respectively. Mass spectra ESI technique (solvents: acetonitrile + water + ammonium acetate) gave $\left(M^{+}+17\right)$ (ammoniated) 228 and $\left(M^{+}\right) \mathrm{m} / \mathrm{z} 211$. Ammonia was identified by use of Nessler's reagent. ${ }^{20}$ The product, Ni(II), remained in the aqueous layer and it was identified by its dimethyl glyoxime complex. ${ }^{21}$

$\mathrm{N}$-(isopropyl) amino carboxylic acid, which is soluble in water, was identified by the spot test. ${ }^{22}$ It was observed that the 4-carboxy methoxy phenyl acetic acid and $\mathrm{N}$-(isopropyl) amino carboxylic acid do not undergo further oxidation under the present kinetic conditions.

\subsection{Spectrofluorimetric studies}

The fluorescence study was carried out in methanol as solvent for good dissolution of the pure and product compound. No interference of the solvent methanol was seen in the fluorescent study. Fluorescence studies of pure compound atenolol and the product of the reaction of atenolol with permanganate in presence of ruthenium (III) catalyst in aqueous alkaline medium were carried out. Excitation for the atenolol was observed at $370 \mathrm{~nm}$ and emission now at $411 \mathrm{~nm}$ with intensity 106 . Excitation of the product was observed at $370 \mathrm{~nm}$ and emission was at $416 \mathrm{~nm}$ with considerable decrease in fluorescent intensity to $36 \cdot 62$, due to quenching.

\subsection{Reaction orders}

As permanganate oxidation of atenolol in alkaline medium proceeds with measurable rate in the absence of ruthenium (III), the catalysed reaction is understood to occur in parallel paths with contributions from both the catalysed and uncatalysed paths. Thus, the total rate constant $\left(k_{T}\right)$ is equal to the sum of the rate constants of the catalysed $\left(k_{C}\right)$ and uncatalysed $\left(k_{U}\right)$ reactions, so $k_{C}=k_{T}-k_{U}$. Hence, the reaction orders have been determined from the slopes of $\log k_{C}$ vs $\log$ concentration plots by varying the concentrations of reductant, $\mathrm{Ru}(\mathrm{III})$, and alkali in turn, while keeping the others constant.

Potassium permanganate concentration was varied in the range of $2.0 \times 10^{-5}$ to $2.0 \times 10^{-4} \mathrm{~mol} \mathrm{dm}^{-3}$, and the linearity of plots of $\log$ absorbance vs time $(r \geq 0.9998, S \leq 0.0131)$ up to $85 \%$ completion of the reaction (figure 2) indicate a reaction order of unity in $\left[\mathrm{MnO}_{4}^{-}\right]$. This is also confirmed by variation of $\left[\mathrm{MnO}_{4}^{-}\right]$, which did not result in any change in the pseudo first-order rate constants, $k_{C}$ (table 1). The substrate concentration was varied in the range $1.0 \times 10^{-3}$ to $1.0 \times 10^{-2} \mathrm{~mol} \mathrm{dm}^{-3}$ at $25^{\circ} \mathrm{C}$, while keeping all other reactant concentrations and conditions constant, including ruthenium (III) catalyst. The $k c$ values increased with increase in concentration of atenolol indicating an apparently less than unit order dependence on [atenolol] (table 1).

Ruthenium (III) concentration was varied in the $8.0 \times 10^{-7}$ to $8 \cdot 0 \times 10^{-6} \mathrm{~mol} \mathrm{dm}^{-3}$ range, at constant concentration of permanganate, atenolol, alkali and ionic strength. The order in $[\mathrm{Ru}(\mathrm{III})]$ is found to be unity (table 1) from the linearity of the plots of $\log$ $k c$ vs $\log [\mathrm{Ru}(\mathrm{III})](r \geq 0.9995, S \leq 0.0122)$. The effect of alkali on the reaction has been studied at constant concentrations of atenolol, potassium permanganate, ruthenium (III) and a constant ionic strength of $0.30 \mathrm{~mol} \mathrm{dm}^{-3}$. The rate constants increased with increasing [alkali] and the order less than unity (table 1).

\subsection{Effect of relative permittivity and ionic strength}

The effect of relative permittivity $\left(\varepsilon_{T}\right)$ on the rate constant has been studied by varying the $t$-butanol-

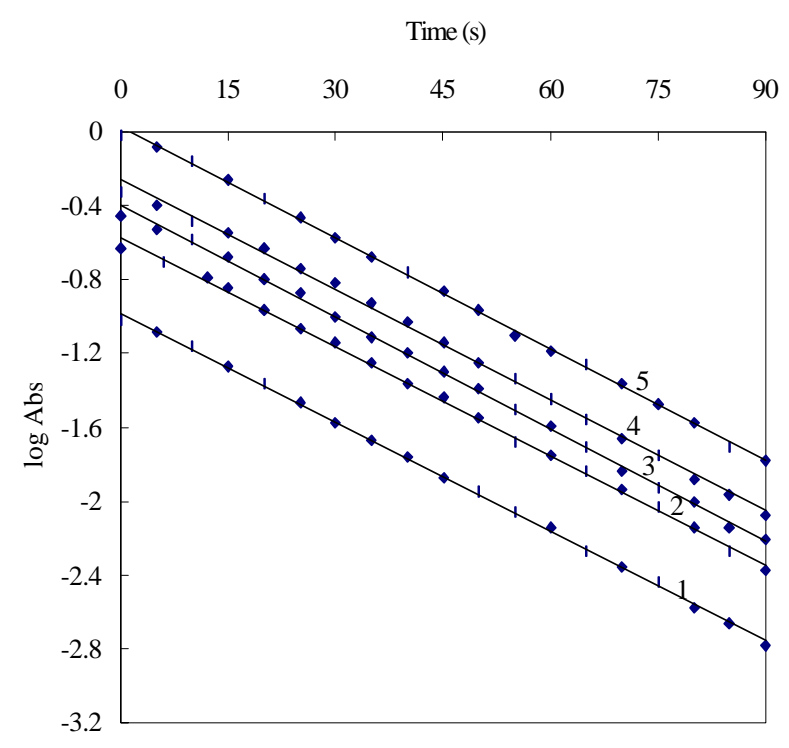

Figure 2. First-order plots of Ru(III)-catalysed oxidation of permanganate by atenolol in aqueous alkaline medium at $25^{\circ} \mathrm{C}$. $\left[\mathrm{MnO}_{4}^{-}\right] \times 10^{4}\left(\mathrm{~mol} \mathrm{dm}^{-3}\right)$; (1) 0.2 , (2) 0.4 , (3) $1 \cdot 0$, (4) $1 \cdot 5$, (5) $2 \cdot 0$. 
Table 1. Effect of variation of $\left[\mathrm{KMnO}_{4}\right]$, [ATN], [Ru(III)] and $[\mathrm{OH}]$ on $\mathrm{Ru}(\mathrm{III})$-catalysed oxidation of atenolol by $\mathrm{KMnO}_{4}$ in aqueous alkaline media at $25^{\circ} \mathrm{C}$ and $I=0.30 \mathrm{~mol} \mathrm{dm}{ }^{-3}$.

\begin{tabular}{|c|c|c|c|c|c|c|c|}
\hline \multirow{2}{*}{$\begin{array}{l}10^{4}\left[\mathrm{MnO}_{4}\right] \\
\left(\mathrm{mol} \mathrm{dm}^{-3}\right)\end{array}$} & \multirow{2}{*}{$\begin{array}{l}10^{3}[\mathrm{ATN}] \\
\left(\mathrm{mol} \mathrm{dm}^{-3}\right)\end{array}$} & \multirow{2}{*}{$\begin{array}{l}10^{6}[\mathrm{Ru}(\mathrm{III})] \\
\left(\mathrm{mol} \mathrm{dm}^{-3}\right)\end{array}$} & \multirow{2}{*}{$\begin{array}{c}{\left[\mathrm{OH}^{-}\right]} \\
\left(\mathrm{mol} \mathrm{dm}^{-3}\right)\end{array}$} & \multicolumn{4}{|c|}{$10^{2}\left(\mathrm{~s}^{-1}\right)$} \\
\hline & & & & $k_{T}$ & $k_{u}$ & $k_{c}$ expt. & $k_{c \text { cal }}$. \\
\hline $0 \cdot 2$ & $1 \cdot 5$ & $1 \cdot 0$ & 0.05 & $4 \cdot 64$ & $1 \cdot 12$ & $3 \cdot 52$ & $3 \cdot 48$ \\
\hline $0 \cdot 4$ & $1 \cdot 5$ & $1 \cdot 0$ & $0 \cdot 05$ & 4.66 & $1 \cdot 14$ & $3 \cdot 52$ & $3 \cdot 48$ \\
\hline $1 \cdot 0$ & 1.5 & $1 \cdot 0$ & 0.05 & 4.67 & $1 \cdot 13$ & 3.54 & $3 \cdot 48$ \\
\hline $1 \cdot 5$ & 1.5 & $1 \cdot 0$ & $0 \cdot 05$ & $4 \cdot 65$ & $1 \cdot 16$ & $3 \cdot 49$ & $3 \cdot 48$ \\
\hline $2 \cdot 0$ & $1 \cdot 5$ & $1 \cdot 0$ & 0.05 & $4 \cdot 62$ & 1.09 & 3.53 & $3 \cdot 48$ \\
\hline $1 \cdot 5$ & 1.0 & $1 \cdot 0$ & 0.05 & $3 \cdot 63$ & 0.86 & 2.77 & $2 \cdot 70$ \\
\hline $1 \cdot 5$ & 1.5 & $1 \cdot 0$ & $0 \cdot 05$ & $4 \cdot 65$ & $1 \cdot 16$ & $3 \cdot 49$ & $3 \cdot 48$ \\
\hline $1 \cdot 5$ & $3 \cdot 0$ & $1 \cdot 0$ & 0.05 & $6 \cdot 99$ & $2 \cdot 04$ & 4.95 & $5 \cdot 02$ \\
\hline $1 \cdot 5$ & $6 \cdot 0$ & 1.0 & 0.05 & $10 \cdot 0$ & $3 \cdot 54$ & $6 \cdot 46$ & $6 \cdot 47$ \\
\hline $1 \cdot 5$ & $1 \cdot 0$ & $1 \cdot 0$ & 0.05 & $13 \cdot 5$ & $5 \cdot 54$ & 7.93 & $7 \cdot 41$ \\
\hline $1 \cdot 5$ & $1 \cdot 5$ & $0 \cdot 8$ & $0 \cdot 05$ & $3 \cdot 97$ & $1 \cdot 16$ & $2 \cdot 81$ & $2 \cdot 78$ \\
\hline $1 \cdot 5$ & $1 \cdot 5$ & $1 \cdot 0$ & 0.05 & $4 \cdot 65$ & $1 \cdot 16$ & $3 \cdot 49$ & $3 \cdot 48$ \\
\hline 1.5 & 1.5 & $2 \cdot 0$ & 0.05 & $8 \cdot 21$ & $1 \cdot 16$ & 7.05 & $6 \cdot 95$ \\
\hline $1 \cdot 5$ & $1 \cdot 5$ & $4 \cdot 0$ & $0 \cdot 05$ & $15 \cdot 3$ & $1 \cdot 16$ & $14 \cdot 2$ & $13 \cdot 9$ \\
\hline $1 \cdot 5$ & $1 \cdot 5$ & $8 \cdot 0$ & 0.05 & $29 \cdot 4$ & $1 \cdot 16$ & $28 \cdot 3$ & $28 \cdot 0$ \\
\hline $1 \cdot 5$ & 1.5 & $1 \cdot 0$ & 0.02 & $2 \cdot 50$ & 0.58 & 1.92 & 1.87 \\
\hline $1 \cdot 5$ & 1.5 & $1 \cdot 0$ & 0.05 & 4.65 & $1 \cdot 16$ & 3.49 & $3 \cdot 48$ \\
\hline $1 \cdot 5$ & $1 \cdot 5$ & $1 \cdot 0$ & $0 \cdot 08$ & $6 \cdot 07$ & $1 \cdot 50$ & $4 \cdot 57$ & 4.43 \\
\hline $1 \cdot 5$ & $1 \cdot 5$ & $1 \cdot 0$ & $0 \cdot 10$ & $6 \cdot 50$ & 1.60 & 4.90 & $4 \cdot 86$ \\
\hline 1.5 & 1.5 & $1 \cdot 0$ & $0 \cdot 20$ & $8 \cdot 00$ & $2 \cdot 01$ & 5.99 & 6.08 \\
\hline
\end{tabular}

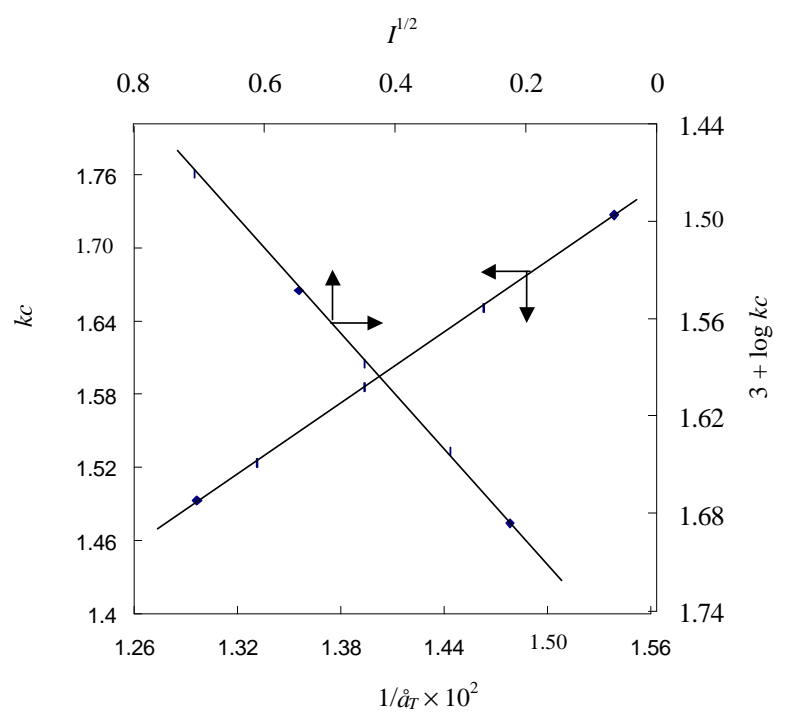

Figure 3. Plots of $\log k_{c}$ vs $I^{1 / 2}$ and $\log k_{c}$ vs $1 / \varepsilon_{T}$. $[\mathrm{ATN}]=1.5 \times 10^{-3},\left[\mathrm{MnO}_{4}^{-}\right]=1.5 \times 10^{-4},[\mathrm{Ru}(\mathrm{III})]=1.0 \times$ $10^{-6},\left[\mathrm{OH}^{-}\right]=0 \cdot 05$, and $I=0 \cdot 30 \mathrm{~mol} \mathrm{dm}{ }^{-3}$ at $25^{\circ} \mathrm{C}$.

water content in the reaction mixture with all other conditions kept constant, including concentration of
$\mathrm{Ru}(\mathrm{III})$ catalyst. Attempts to measure the relative permittivities were not successful. However, they were computed from the values of pure liquids. ${ }^{23}$ No reaction of the solvent with the oxidant occurs under the experimental conditions employed. The rate constant, $k_{C}$, increases with decreasing relative permittivity of the medium. The plot of $\log k_{C}$ vs $1 / \varepsilon_{T}$ is linear with a positive slope (figure 3$)(r \geq 0.9989$, $S \leq 0 \cdot 0141$ ).

The effect of ionic strength was studied by variation of the $\mathrm{NaClO}_{4}$ concentration in the reaction medium. The ionic strength was varied from 0.05 to $0.5 \mathrm{~mol} \mathrm{dm}^{-3}$ at constant concentrations of permanganate, atenolol, ruthenium (III) and alkali. It is found that the rate constant decreases with increasing concentration of $\mathrm{NaClO}_{4}$. The plot of $\log k_{C}$ vs $I^{1 / 2}$ is linear with a negative slope (figure 3) $(r \geq 0.9997, S \leq 0.0112)$.

\subsection{Effect of initially added products}

The initially added products, such as manganate, and 4-carboxy methoxy phenyl acetic acid, do not have any significant effect on the rate of the reaction. 
Table 2. Thermodynamic activation parameters for $\mathrm{Ru}(\mathrm{III})$-catalysed oxidation of alkaline permanganate by atenolol in alkaline media with respect to the slow step of scheme 3 .

\begin{tabular}{llllll}
\hline (a) Effect of temperature & & & & & \\
\hline Temp. $(\mathrm{K})$ & 298 & 303 & 308 & 313 & 318 \\
$k \times 10^{-5}\left(\mathrm{dm}^{3} \mathrm{~mol}^{-1} \mathrm{~s}^{-1}\right)$ & 2.10 & 2.31 & 2.51 & 2.75 & 2.99 \\
\hline
\end{tabular}

(b) Effect of temperature on $K_{1}$ in Ru(III)-catalysed oxidation of alkaline permanganate by atenolol in alkaline medium

\begin{tabular}{|c|c|c|c|c|c|}
\hline Temp. (K) & 298 & 303 & 308 & 313 & 318 \\
\hline$K_{1}\left(\mathrm{dm}^{3} \mathrm{~mol}^{-1}\right)$ & 15.0 & 18.3 & 21.6 & 25.1 & 29.4 \\
\hline
\end{tabular}

(c) Activation parameters

\begin{tabular}{lccccc}
\hline Parameters & $E_{a}\left(\mathrm{~kJ} \mathrm{~mol}^{-1}\right)$ & $\log A$ & $\Delta H^{\#}\left(\mathrm{~kJ} \mathrm{~mol}^{-1}\right)$ & $\Delta S^{\#}\left(\mathrm{JK}^{-1} \mathrm{~mol}^{-1}\right)$ & $\Delta G^{\#}\left(\mathrm{~kJ} \mathrm{~mol}^{-1}\right)$ \\
Catalysed reaction $^{16}$ & $13 \cdot 7 \pm 0 \cdot 7$ & $7 \cdot 74 \pm 0 \cdot 4$ & $11 \cdot 2 \pm 0 \cdot 6$ & $-25 \cdot 1 \pm 1 \cdot 3$ & $18 \cdot 8 \pm 1 \cdot 0$ \\
Uncatalysed reaction $^{16}$ & $24 \pm 3$ & - & $21 \pm 3$ & $-200 \pm 10$ & $82 \pm 4$ \\
\hline
\end{tabular}

(d) Thermodynamic quantities for the first equilibrium of scheme 3

\begin{tabular}{lccc}
\hline Thermodynamic quantities & $\Delta H\left(\mathrm{~kJ} \mathrm{~mol}^{-1}\right)$ & $\Delta S\left(\mathrm{JK}^{-1} \mathrm{~mol}^{-1}\right)$ & $\Delta G\left(\mathrm{~kJ} \mathrm{~mol}^{-1}\right)$ \\
Values & $25.9 \pm 1 \cdot 4$ & $110 \pm 6$ & $-7 \cdot 8 \pm 0.4$ \\
\hline
\end{tabular}

\subsection{Test for free radicals}

To test for the intervention of free radicals, the reaction mixture was mixed with acrylonitrile monomer and kept for $24 \mathrm{~h}$ under nitrogen atmosphere. On dilution with methanol, white precipitate of polymer was formed, indicating that intervention of free radicals in the reaction does occur. The blank experiment of reacting either permanganate and ruthenium (III) or atenolol and ruthenium (III) alone with acrylonitrile did not induce polymerization under the same conditions. Initially added acrylonitrile decreases the rate indicating free radical intervention, as in the earlier work. ${ }^{24}$

\subsection{Effect of temperature}

Rates of reaction were measured at different temperatures under varying atenolol concentrations. Rate of reaction increases with increase of temperature. The rate constants, $k$, of the slow step of scheme 3 are obtained from the slope of the plot of $[\mathrm{Ru}(\mathrm{III})] / k c$ vs $1 /$ [atenolol] $(r \geq 0.9996, S \leq 0.0121)$ and used to calculate the activation parameters. The values of $k\left(\mathrm{dm}^{3} \mathrm{~mol}^{-1} \mathrm{~s}^{-1}\right)$ are given in table 2 . The activation parameters corresponding to these constants were evaluated from the plot of $\log k$ vs $1 / T$ $(r \geq 0.9989, S \leq 0.0135)$ and are tabulated in table 2 .

\section{Discussion}

Permanganate ion, $\mathrm{MnO}_{4}^{-}$, is a powerful oxidant in aqueous alkaline media. As it exhibits many oxidation states, the stoichiometric results and $\mathrm{pH}$ of the reaction media play important roles. Under the prevailing experimental conditions at $\mathrm{pH}>12$, the reduction product of $\mathrm{Mn}(\mathrm{VII})$, i.e. $\mathrm{Mn}(\mathrm{VI})$, is stable and further reduction of $\mathrm{Mn}(\mathrm{VI})$ might be stopped. ${ }^{10,11}$ Diode array rapid scan spectrophotometric (DARSS) studies have shown that at $\mathrm{pH}>12$, the product of $\mathrm{Mn}(\mathrm{VII})$ is $\mathrm{Mn}(\mathrm{VI})$ and no further reduction is observed as reported by Simandi et al. ${ }^{10}$ However, on prolonged standing, the green $\mathrm{Mn}(\mathrm{VI})$ is reduced to $\mathrm{Mn}(\mathrm{IV})$ under our experimental conditions.

Permanganate in alkaline media exhibits various oxidation states, such as $\mathrm{Mn}(\mathrm{VII}), \mathrm{Mn}(\mathrm{V})$ and $\mathrm{Mn}(\mathrm{VI})$. The colour of the solution changes from violet to blue and further to green excluding the accumulation of hypomanganate. The violet colour originates from the pink of the permanganate and the blue from the hypomanganate during the course of the reaction. Colour change in the $\mathrm{KMnO}_{4}$ solution from the violet $\mathrm{Mn}(\mathrm{VII})$ ion to the dark green $\mathrm{Mn}(\mathrm{VI})$ ion through the blue $\mathrm{Mn}(\mathrm{IV})$ ion has been observed.

It is interesting to identify the probable species of ruthenium(III) chloride in alkaline media. Electronic spectral studies $^{25}$ have confirmed that ruthenium 
(III) chloride exists in hydrated form as $\left[\mathrm{Ru}\left(\mathrm{H}_{2} \mathrm{O}\right)_{6}\right]^{3+}$. In the present study in alkaline media it is quite probable that the species $\left[\mathrm{Ru}\left(\mathrm{H}_{2} \mathrm{O}\right)_{5} \mathrm{OH}\right]^{2+}$ might assume the general form $\left[\mathrm{Ru}^{\text {III }}(\mathrm{OH})_{x}\right]^{3-x}$. The value of $x$ would always be less than six because there are no definite reports of any hexahydroxy species of ruthenium. The remainder of the coordination sphere is filled by water molecules. Hence under the experimental conditions $\left[\mathrm{OH}^{-}\right] \gg\left[\mathrm{Ru}^{\mathrm{III}}\right]$, ruthenium (III) is mostly present ${ }^{26}$ as the hydroxylated species, $\left[\mathrm{Ru}\left(\mathrm{H}_{2} \mathrm{O}\right)_{5} \mathrm{OH}\right]^{2+}$.

The reaction between permanganate and atenolol in alkaline media in presence of ruthenium (III) has the stoichiometry of $1: 8$ with first-order dependence on $\left[\mathrm{MnO}_{4}^{-}\right]$and [ruthenium (III)] and less than unitorder dependence on both [alkali] and [atenolol]. No effect of added products is observed. The apparent order of less than unity in $\left[\mathrm{OH}^{-}\right]$may be an indication of the formation of permanganate species as alkali permanganate, $\mathrm{MnO}_{4} \cdot \mathrm{OH}^{2-}$, from permanganate ion in a prior-equilibrium step. ${ }^{27,28}$ Formation of the $\mathrm{MnO}_{4} \cdot \mathrm{OH}^{2-}$ species in alkaline media was further supported by the Michaelis-Menten plot (figure 4) which is linear with a positive intercept. Based on the experimental results, a mechanism can be proposed in which all the observed orders with respect to each constituent such as oxidant, catalyst, reductant and $\mathrm{OH}^{-}$may be well accommodated. Here the hydroxylated species of ruthenium (III) reacts with

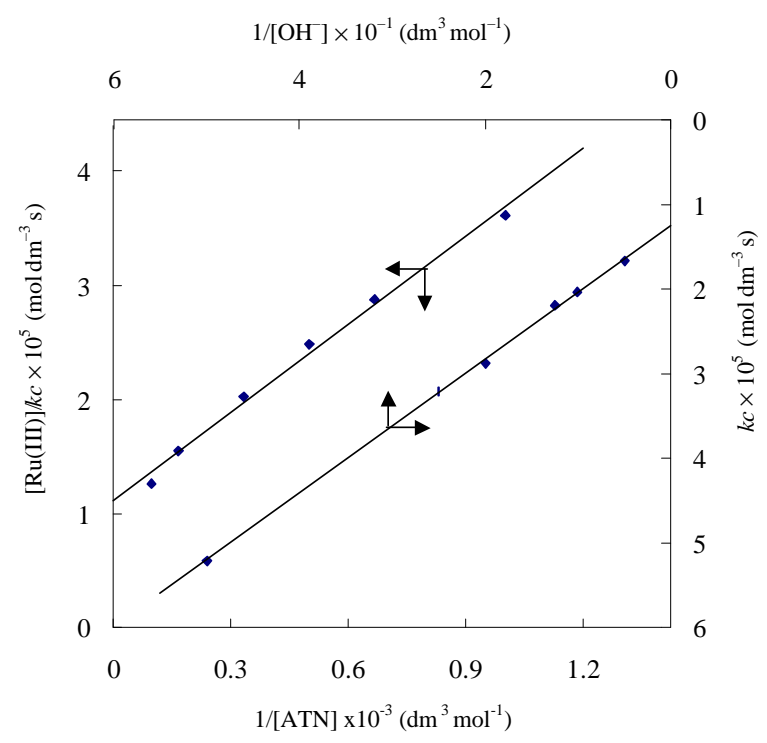

Figure 4. Verification of rate law (2) in the form of (3) (conditions as in table 1).
ATN to give a complex (C), which reacts with one mole of the alkali permanganate species in a slow step to form a free radical derived from atenolol and the product $\mathrm{MnO}_{4}^{2-}$ with regeneration of catalyst, ruthenium (III). Such complex formation between substrate and catalyst has also been observed in earlier work, ${ }^{29,30}$ which is also supported by the observed fractional order in $\left[\mathrm{OH}^{-}\right]$and [atenolol]. The free radical derived from atenolol combines with permanganate species in a fast step to form a diol. This diol reacts with six more moles of permanganate species in further fast steps to yield the products shown in scheme 3 .

The probable structure of the complex $(\mathrm{C})$ is given in chart 1.

Spectral evidence for such a catalyst-substrate complex was obtained from the UV-Vis spectra of atenolol and a mixture of ruthenium (III) and atenolol. A hypsochromic shift, $\lambda_{\max }$, of $\approx 5 \mathrm{~nm}$ from 343 to $338 \mathrm{~nm}$ is observed together with hyperchromicity at $338 \mathrm{~nm}$.

The thermodynamic quantities for the first equilibrium step in scheme 3 can be evaluated as follows. The hydroxyl ion concentration (as in table 1) is varied at different temperatures. The plots of $[\mathrm{Ru}(\mathrm{III})] / k_{c}$ vs $1 /\left[\mathrm{OH}^{-}\right](r \geq 0.9999, S \leq 0 \cdot 0113)$ should be linear as shown in figure 4 . From the slopes and intercepts, the values of $K_{1}$ are calculated at different temperatures and are given in table 2. A vant Hoff plot was made for the variation of $K_{1}$ with temperature [i.e., $\log K_{1}$ versus $\left.1 / T(r \geq 0.9998, S \leq 0.0128)\right]$ and the values of the enthalpy of reaction $\Delta H$, entropy of reaction $\Delta S$ and free energy of reaction $\Delta G$, were calculated. These values are also given in table 2. A comparison of the latter values with those obtained for the slow step of the reaction shows that these values mainly refer to the rate-limiting step, supporting the fact that the reaction before the rate-determining step is fairly slow and involves high activation energy. ${ }^{31}$

In the presence of catalyst, the reaction is understood to occur in parallel paths with contributions from the uncatalysed and catalysed paths. Thus the

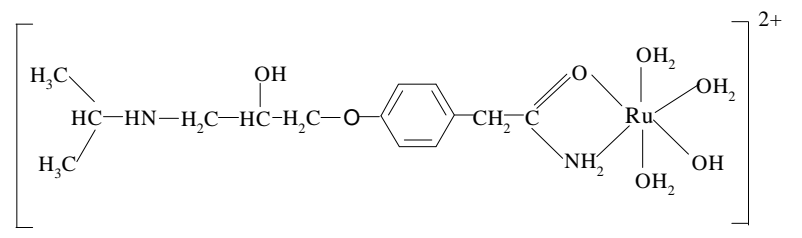

Chart 1. 


$$
\mathrm{Mnc}_{4}+\mathrm{OH}^{-}=\left[\mathrm{K}^{2}-\left[\|_{\mathrm{O}}^{\mathrm{O}=}\right]_{\mathrm{O}}^{\mathrm{O}}\right]^{2-}
$$
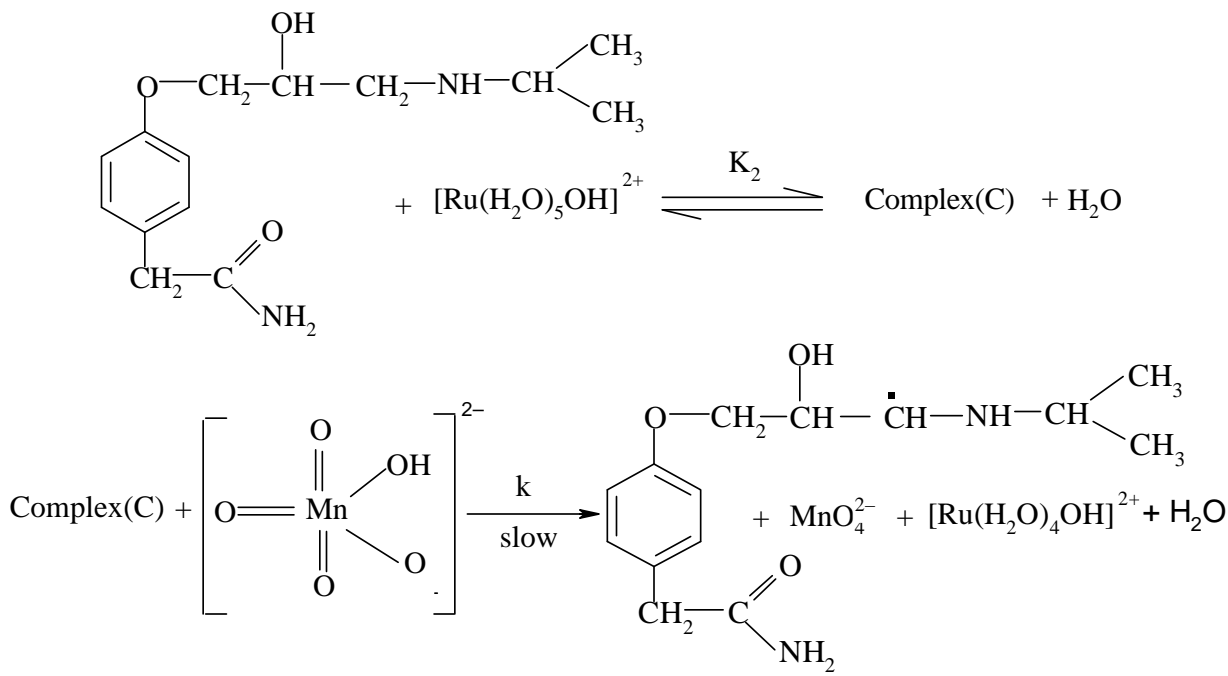<smiles>CC(C)NC(O)C(O)COc1ccc(CC(N)=O)c(C(C)C)c1</smiles><smiles>CC(C)NC(O)C(O)COc1ccc(CC(=O)[O-])cc1</smiles>

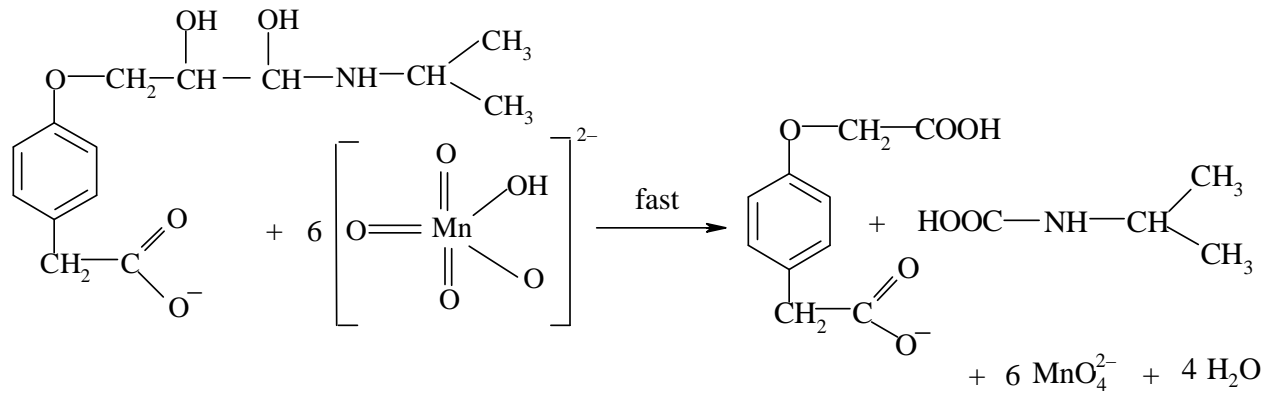

Scheme 3. 
total rate constant $\left(k_{T}\right)$ is equal to the sum of the rate constants of the catalysed $\left(k_{c}\right)$ and uncatalysed $\left(k_{u}\right)$ reactions:

$$
\text { rate }_{\text {cat }}=\text { rate }_{\text {total }}-\text { rate }_{\text {uncat }} \text {. }
$$

Scheme 3 leads to the rate law (3) below.

$$
\begin{aligned}
& \text { Rate }=-\frac{\mathrm{d}\left[\mathrm{MnO}_{4}^{-}\right]}{\mathrm{d} t}= \\
& \frac{k K_{1} K_{2}[\mathrm{ATN}]_{T}\left[\mathrm{MnO}_{4}^{-}\right]_{T}[\mathrm{Ru}(\mathrm{III})]_{T}\left[\mathrm{OH}^{-}\right]_{T}}{\left(1+K_{2}[\mathrm{ATN}]\right)\left(1+K_{2}[\mathrm{Ru}(\mathrm{III})]\right)\left(1+K_{1}\left[\mathrm{MnO}_{4}^{-}\right]\right)\left(1+K_{1}\left[\mathrm{OH}^{-}\right]\right)} .
\end{aligned}
$$

The terms $\left(1+K_{1}\left[\mathrm{MnO}_{4}^{-}\right]\right)$and $\left(1+K_{2}[\mathrm{Ru}(\mathrm{III})]\right)$ in the denominator of (2) approximate to unity in view of the low concentrations of $\mathrm{MnO}_{4}^{-}$and ruthenium (III) used (omitting the subscripts $T$ and $f$ ). In terms of rate constants,

$$
\begin{aligned}
& \frac{\text { rate }}{\left[\mathrm{MnO}_{4}^{-}\right]}=k_{C}=k_{T}-k_{U} \\
& \frac{K K_{1} K_{2}[\mathrm{ATN}][\mathrm{Ru}(\mathrm{III})]\left[\mathrm{OH}^{-}\right]}{1+K_{1}\left[\mathrm{OH}^{-}\right]+K_{2}[\mathrm{ATN}]+K_{1} K_{2}\left[\mathrm{OH}^{-}\right][\mathrm{ATN}]} .
\end{aligned}
$$

Equation (3) can be rearranged to the following form, which is used for the verification of the rate law.

$$
\begin{aligned}
& \frac{[\mathrm{Ru}(\mathrm{III})]}{k_{C}}=\frac{1}{k K_{1} K_{2}[\mathrm{ATN}]\left[\mathrm{OH}^{-}\right]} \\
& +\frac{1}{k K_{2}[\mathrm{ATN}]}+\frac{1}{k K_{1}\left[\mathrm{OH}^{-}\right]}+\frac{1}{k} .
\end{aligned}
$$

According to (4), the plots of $[\mathrm{Ru}(\mathrm{III})] / k_{c}$ versus $1 /[\mathrm{ATN}]$ and $[\mathrm{Ru}(\mathrm{III})] / k_{c}$ versus $1 /\left[\mathrm{OH}^{-}\right] \quad(r \geq$ $0.9996, S \leq 0.0121)$ and $(r \geq 0.9999, S \leq 0.0113)$ are linear with an intercept supporting the $\mathrm{Ru}(\mathrm{III})$ atenolol complex, and which is verified in figure 4 . From the slope and intercept of such plots, the values of $K_{1}, K_{2}$ and $k$ are calculated to be $15.0 \pm 0.75 \mathrm{dm}^{3}$ $\mathrm{mol}^{-1}, 4 \cdot 20 \pm 0 \cdot 21 \times 10^{2} \mathrm{dm}^{3} \mathrm{~mol}^{-1}$ and $2 \cdot 10 \pm 0 \cdot 1 \times$ $10^{5} \mathrm{dm}^{3} \mathrm{~mol}^{-1} \mathrm{~s}^{-1}$. The value of $K_{1}$ is in agreement with the earlier value. ${ }^{32}$ Using these $K_{1}, K_{2}$ and $k$ values, the rate constants under different experimental conditions were calculated by (3) and compared with experimental data, with which there is good agreement (table 1).

The difference in the activation parameters for the catalysed $\left(k_{c}\right)$ and uncatalysed $\left(k_{u}\right)$ reactions (table 2 ) explains the catalytic effect on the reaction. The catalyst, $\mathrm{Ru}(\mathrm{III})$, forms a complex with atenolol that is more reducible than atenolol itself. Hence, the catalyst lowers the energy of activation. The negative value of $\Delta S^{\#}$ indicates that the complex (C) is more ordered than the reactants. ${ }^{33}$ The observed modest enthalpy of activation and the higher rate constant of the slow step (compared to $k_{c}$ ) indicate that the oxidation presumably occurs by inner-sphere mechanism. This conclusion is supported by earlier work. ${ }^{34,35}$

The effect of ionic strength on the rate can be understood essentially on the basis of ionic species as in scheme 3. The effect of solvent on the reaction rate has been described in detail in the literature. ${ }^{36}$ Increasing the content of $t$-butanol in the reaction medium leads to an increase in the rate of reaction, which seems to be contrary to the expected interaction between neutral and anionic species in media of lower relative permittivity. However, an increase in the rate of reaction with decreasing dielectric constant may be due to stabilization of the complex (C) at low relative permittivity, which is less solvated than $\mathrm{MnO}_{4}^{-}$at higher dielectric constant because of its larger size. Spectrofluorimetric studies reveal that the fluorescence intensity is quenched, which may be due to the electron transfer reaction. ${ }^{37}$

\section{Conclusion}

It is interesting that the oxidant species $\left[\mathrm{MnO}_{4}^{-}\right]$requires a $\mathrm{pH}>12$ for reaction, below which the system becomes disturbed and the reaction proceeds further to give the reduced product of the oxidant, $\mathrm{Mn}(\mathrm{IV})$, which slowly develops yellow turbidity. Hence, it becomes apparent that in carrying out this reaction the role of $\mathrm{pH}$ in a reaction medium is crucial. It is also noteworthy that under the conditions studied, the reaction occurs as two successive one-electron reductions (scheme 3 ) rather than as a two-electron reduction in a single step (scheme 2). Ruthenium (III) is known to be an efficient catalyst especially in alkaline media, a micro amount of ruthenium (III) is sufficient to catalyse the title reaction with measurable rate. The overall mechanistic sequence described here is consistent with products, mechanistic and kinetic studies.

\section{Appendix A}

According to scheme 3

$$
\begin{aligned}
& \text { rate }_{\text {cat }}=\text { rate }_{\text {total }}-\text { rate }_{\text {uncat }} \\
& =k K_{1} K_{2}[\mathrm{ATN}]_{f}\left[\mathrm{MnO}_{4}^{-}\right]_{f}\left[\mathrm{OH}^{-}\right]_{f}[\mathrm{Ru}(\mathrm{III})]_{f} .
\end{aligned}
$$


The total concentration of atenolol $[\mathrm{ATN}]_{T}$, is given by (subscripts $T$ and $f$ stand for total and free),

$$
\begin{aligned}
{\left[\mathrm{ATN}_{T}\right.} & =[\mathrm{ATN}]_{f}+[\mathrm{C}] \\
& =[\mathrm{ATN}]_{f}+K_{2}[\mathrm{ATN}]_{f}[\mathrm{Ru}(\mathrm{III})] \\
& =[\mathrm{ATN}]_{f}\left(1+K_{2}[\mathrm{Ru}(\mathrm{III})]\right) .
\end{aligned}
$$

Therefore,

$$
[\mathrm{ATN}]_{f}=[\mathrm{ATN}]_{T} /\left(1+K_{2}[\mathrm{Ru}(\mathrm{III})]\right) .
$$

Similarly,

$$
\begin{aligned}
& {\left[\mathrm{OH}^{-}\right]_{f}=\left[\mathrm{OH}^{-}\right]_{T} /\left(1+K_{1}\left[\mathrm{MnO}_{4}^{-}\right]\right),} \\
& {[\mathrm{Ru}(\mathrm{III})]_{f}=\left[\mathrm{Ru}(\mathrm{III})^{-}\right]_{T} /\left(1+K_{2}\left[\mathrm{ATN}^{-}\right]\right),} \\
& {\left[\mathrm{MnO}_{4}^{-}\right]_{f}=\left[\mathrm{MnO}_{4}^{-}\right]_{T} /\left(1+K_{1}\left[\mathrm{OH}^{-}\right]\right) .}
\end{aligned}
$$

Substituting (A2)-(A5) in (A1) we get

$$
\begin{aligned}
& \text { rate }=-\frac{\mathrm{d}\left[\mathrm{MnO}_{4}^{-}\right]}{\mathrm{d} t}= \\
& \frac{k K_{1} K_{2}[\mathrm{ATN}]_{T}\left[\mathrm{MnO}_{4}^{-}\right]_{T}[\mathrm{Ru}(\mathrm{III})]_{T}\left[\mathrm{OH}^{-}\right]_{T}}{\left(1+K_{2}[\mathrm{ATN}]\right)\left(1+K_{2}[\mathrm{Ru}(\mathrm{III})]\right)\left(1+K_{1}\left[\mathrm{MnO}_{4}^{-}\right]\right)\left(1+K_{1}\left[\mathrm{OH}^{-}\right]\right)} .
\end{aligned}
$$

\section{References}

1. Stewart R 1965 In Oxidation in organic chemistry Part A (eds) K B Wiberg (New York: Academic Press)

2. Freeman F 1976 Rev. React. Species Chem. React. 1 179

3. Lee D G 1980 Oxidations of organic compounds by permanganate ion and hexavalent chromium (La Salle, IL: Open Court)

4. Lee D G 1982 In Oxidation in organic chemistry Part D (ed.) W S Trahanovsky (New York: Academic Press) p. 147

5. Simandi L I 1983 In The chemistry of functional groups (eds) S Patti and Z Rappoport (Chichester: Wiley), suppl. ch. 13

6. Lee D G, Lee E J and Brown K C 1987 Phase transfer catalysis, new chemistry, catalysts and applications ACS symposium series No. 326 (Washington DC: Am. Chem. Soc.) p. 82

7. Fatiadi A J 1987 Synthesis 10685

8. Perez-Benito J F and Lee D G 1987 J. Org. Chem. 52 3239

9. Gardner K A, Kuehnert L L and Mayer J M 1997 Inorg. Chem. 362069

10. Simandi L I, Jaky M, Savage C R and Schelly Z A 1985 J. Am. Chem. Soc. 1074220

11. Nadimpalli S, Rallabandi R and Dikshitulu L S A 1993 Transition Met. Chem. 18510
12. Panari R G, Chougale R B and Nandibewoor S T 1998 Pol. J. Chem. 7299

13. White M, Fourney A, Mikes E and Leenen F H H 1999 Am. J. Hypertension 12151

14. Swarnalaxmi N, Uma V, Sethuram B and Navaneeth Rao T 1987 Indian J. Chem. A26 592

15. Bailar J C, Emeleus H J, Nyholm R S and Dickenson A F 1975 Comprehensive inorganic chemistry (Oxford: Pergamon) vol. 3, p. 810

16. Gurubasavaraj H M, Kulkarni R M and Nandibewoor S T 2003 J. Chem. Soc., Perkin Trans. II (communicated)

17. Jeffery G H, Bassett J, Mendham J and Denney R C 1996 Vogel's text book of quantitative chemical analysis 5th edn (Essex, UK: ELBS, Longman) p. 371

18. Carrington A and Symons M C R 1956 J. Chem. Soc. 3373

19. Reddy C S and Vijayakumar T 1995 Indian J. Chem. A34 615; 1970 Chem. Abstr. 7250624

20. Ref. 17 , p. 679

21. Ref. 17, p. 462

22. Feigl F 1975 Spot tests in organic analysis (Amsterdam: Elsevier) p. 250

23. Lide D R (ed.) 1992 CRC hand book of chemistry and physics 73rd edn (London: CRC Press) pp. 8-51

24. Bhattacharya S and Benerjee P 1996 Bull. Chem. Soc. Jpn. 693475

25. Cotton F A and Wilkinson G 1996 Advanced inorganic chemistry (New York: Wiley Eastern) p. 153

26. Kamble D L and Nandibewoor S T 1998 J. Phys. Org. Chem. 11171

27. Panari R G, Chougale R B and Nandibewoor S T 1998 J. Phys. Org. Chem. 11448

28. Vivekanandan S, Venkatarao K, Sanatappa M and Shanmuganathan S P 1983 Indian J. Chem. A22 244

29. Rao S V and Jagannadham V 1985 React. Kinet. Catal. Lett. 27239

30. Upadyaya S K and Agarwal M C 1980 Indian J. Chem. A19 478

31. Rangappa K S, Raghavendra M P, Mahadevappa D S and Channagouda D 1998 J. Org. Chem. 63531

32. Chimatadar S A, Kini A K and Nandibewoor S T 2003 Indian J. Chem. A42 1850

33. Weissberger A 1974 Investigation of rates and mechanism of reactions in techniques of chemistry (ed.) E S Lewis (New York: Wiley Interscience) vol. 4, p. 421

34. Martinez M, Pitarque M A and Eldik R V $1996 J$. Chem. Soc., Dalton Trans. 2665

35. Farokhi S A and Nandibewoor S T 2003 Tetrahedron 567595

36. Amis E S 1966 Solvent effects on reaction rates and mechanisms (New York: Academic Press)

37. Lakowicz J R 1986 Principles of fluorescence spectroscopy (New York: Plenum) p. 257 